\title{
Teaching Reform of Adult Correspondence Education Based on Practical Projects Using the Example of the "Principle and Knowledge of Database" Course
}

\author{
Fang Hu*, Xiao Cai, Jun Deng \\ Sichuan Staff University of Science and Technology, Sichuan, China \\ Email: ^hf_sc@126.com
}

How to cite this paper: $\mathrm{Hu}, \mathrm{F}$., Cai, X. and Deng, J. (2019) Teaching Reform of Adult Correspondence Education Based on Practical Projects Using the Example of the "Principle and Knowledge of Database" Course. Open Access Library Journal, 6: e5306.

https://doi.org/10.4236/oalib.1105306

Received: March 4, 2019

Accepted: March 24, 2019

Published: March 27, 2019

Copyright $\odot 2019$ by author(s) and Open Access Library Inc.

This work is licensed under the Creative Commons Attribution International License (CC BY 4.0).

http://creativecommons.org/licenses/by/4.0/

\begin{abstract}
The course of "principle and knowledge of database" plays an important role in computer science education. Adult correspondence education has its inherent characteristics compared with education received by ordinary college students. This study analyzes the general problems encountered in the course teaching. Aiming at the characteristics of adult education, we start from the selection of case studies and the proper planning of the course content, followed by putting forward specific measures for teaching reform based on actual projects. Lastly, opinions on the prospective of the course reform are presented.
\end{abstract}

\section{Subject Areas}

Education

\section{Keywords}

Adult Correspondence Education, Database Course, Education Reform, Computer Science

\section{Characteristics of Adult Education}

Adult education is an important part of lifelong education in China. From the perspective of pedagogy, adults' cognitive ability and learning ability have reached a relatively mature level. They have cognition about the surrounding and can conduct self-learning, which should be fully considered in setting teaching objectives and planning for adult education. Adult students have certain life expe- 
rience and work experience, which are important resources for their study [1]. Most adult education receivers have clear goals and hope to improve their ability to solve practical problems through systematic learning, thereby improving their professional competitiveness. They have strong motivation, and the teaching could be objectively evaluated based on their own standards; during the learning process, they are inclined to select specific learning content as well as effective learning methods according to their own needs. The particularity of adult education directly determines the difference between the teaching content and objectives of adult students and those of ordinary college students [2].

\section{Problems Encountered in Teaching}

With the popularity of big data and AI, database technology is becoming increasingly important in computer science. The principle and application of the database is a compulsory course for students of all majors in the Information Engineering Department in our school. After years of teaching practice, we combine the characteristics of this course and the specific needs of our students, summarizing the following existing problems during the teaching:

1) Knowledge is scattered and the correlation is not strong. The knowledge taught is interspersed in various chapters, which is trivial and fragmentary; moreover, examples of each knowledge point are quite abstract. This problem is prone to influence students, enabling them to master a single knowledge point, but unfamiliar with the whole database system [3].

2) Students do not integrate the principle, design and application of the database well, and lack the comprehensive knowledge of database theory and technology. Although the course study is completed, the lack of training in application system programming results in poor database performance and weak practicality of students' works.

3) The related courses are loosely connected. The teaching of software development and database courses are independent. Students have insufficient ability in mastering overall database design and application interaction. They show weak database application ability in actual project development.

4) During self-learning, most students may directly skip the study of theoretical knowledge and jump to the hands-on practices due to the difficulty in understanding complicated and bothersome theories.

\section{Reform Measures}

1) After the course teaching plan is issued, the course slides, reference materials, learning key points and videos as well as other materials of the course will become available on the online teaching platform (http://sckzd.fanya.chaoxing.com/portal). We also offer Q\&A online at regular intervals and would set up discussion seminar on the platform. In the face-to-face class teaching, we closely pay attention to the focus of the course and carefully teach the application requirement analysis, important operation of the database with the examples including a va- 
riety of queries, and results post-processing and presentation. Through online and offline learning, the overall application of the database is grasped.

2) We carefully select typical case studies with strong practical guidance.

For example, we taught students engaged insafety production and management in Sichuan Province before in 2017. At that time, our school undertook the research project of "Sichuan Province Safety Production Management Talents Research", and we completed the corresponding online application system where the enterprises and institutions within the whole province were required to submit the information. We assumed that it would a good application scenario for our students to master database skills due to the following reasons. First, students are familiar with this system. Second, the application system is not quite complicated. Considering the fact that the majority of our students graduated from junior colleges, the system should be small in scale, but covers most of the knowledge points required in this course. We eventually decided to use this system as a teaching case, mainly training students indata input, query and simple statistics and presenting the basic as well as advanced operation of the system step by step. We also have another popular and effective study-auxiliary case, which is the teaching management system of a community school for the aged in Chengdu completed by teachers from the Information Engineering Department in our school.

3) We improve the learning process of theoretical knowledge. Database technology theory knowledge has a very important guiding role in software system development and database application. In teaching, students can easily feel bored of memorizing and understanding the theory. Although detailed learning materials have been released before the class, according to previous experience, the effect of self-learning is usually very poor, and it is difficult to combine the theory with practical application. Teachers are required to place emphasis on the relationship between database theory knowledge and practical issue solving during teaching. Through such teaching style, students could recognize the importance of theoretical knowledge learning in the process of implementing various functions of application cases.

For example, a major focus of the course is the relation standardization theory, which is the theoretical guidance for database logic design. When implementing a database application, if the standardization is not strictly followed, the data will become abnormal and faults would be reported. When teaching the conceptual model design and logical structure design, we will make the relationship standardization theory integrated into the real cases, and explain the content bit by bit with a large number of examples, so that students can naturally sense the guiding role of the theory.

Here a table is given with information redundancy, which is TbStudent (Stu_No, SName, Sex, ID_card, Password, Cellphone, Addr, CourseNumber, CourseName, Teachers, score). After standardization, the simplified table and relations is presented in Figure 1. Through detailed explanation and hands-on practices, students are guided to mater such theory. 


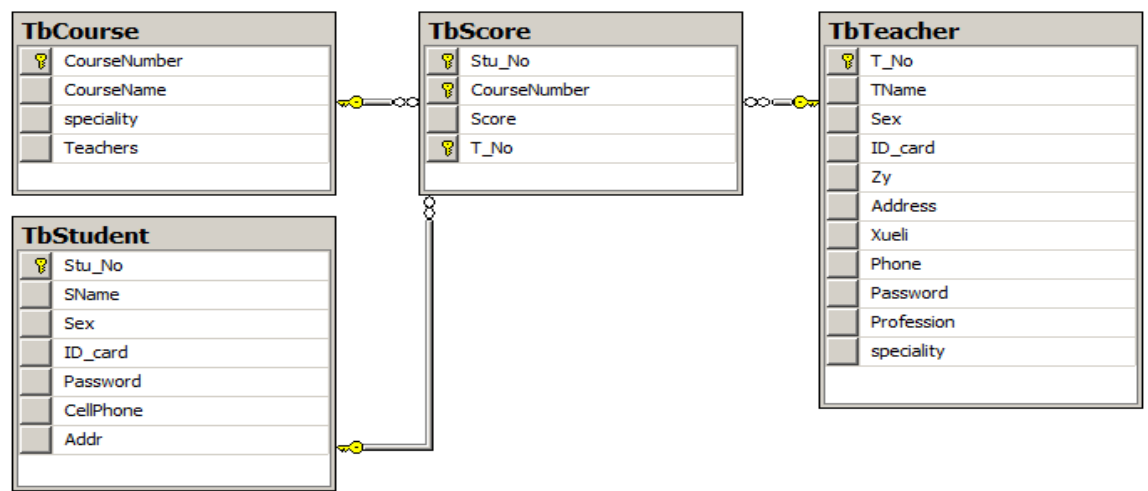

Figure 1. Table relations after standardization.

4) Optimized planning of course content [4] [5].

The database system platform adopted by the course is SQL Server 2008. And our content planning below is based on this platform. In this part we will elaborate on our teaching plans.

The first part is the DBMS operation. The course content matches the actual design and development process of a database system.

a) Demand analysis

At this stage, the function of system is decomposed according to the actual application environment, and the data flow is confirmed. Then, the data flow graph of each application is determined in order to form a data dictionary.

b) Conceptual model design

At this stage, the basic ER model of the system is established according to the data flow graph and the data dictionary.

c) Logical structure design

The ER model is then transformed into the corresponding relation model, and the standardization theory is applied to optimize the logical model.

d) Physical design

This part contains the database establishment and maintenance such as new database creation, library modification and database deletion. It also contains the establishment and maintenance of data tables such as new table and relation creation \& deletion. The results of the case demonstration are shown in Figure 2. Another significant focus is the basic operation of tables such as the various uses of queries.

The second part is accessing the database from the application. The content includes establishing connection, executing a SQL query, and post-analysis on the results of the SQL command execution. Figure 3 shows commands of connecting and closing the database in C\#. Figure 4 shows the method of executing the query and returning the Datatable object using C\#. Figure 5 illustrates the code of C\# executing the SQL with parameters, completing the operation of inserting, deleting and updating records.

The third part is about the query optimization, views, stored procedures, transaction and trigger, etc., which includes visualization of the implementation 

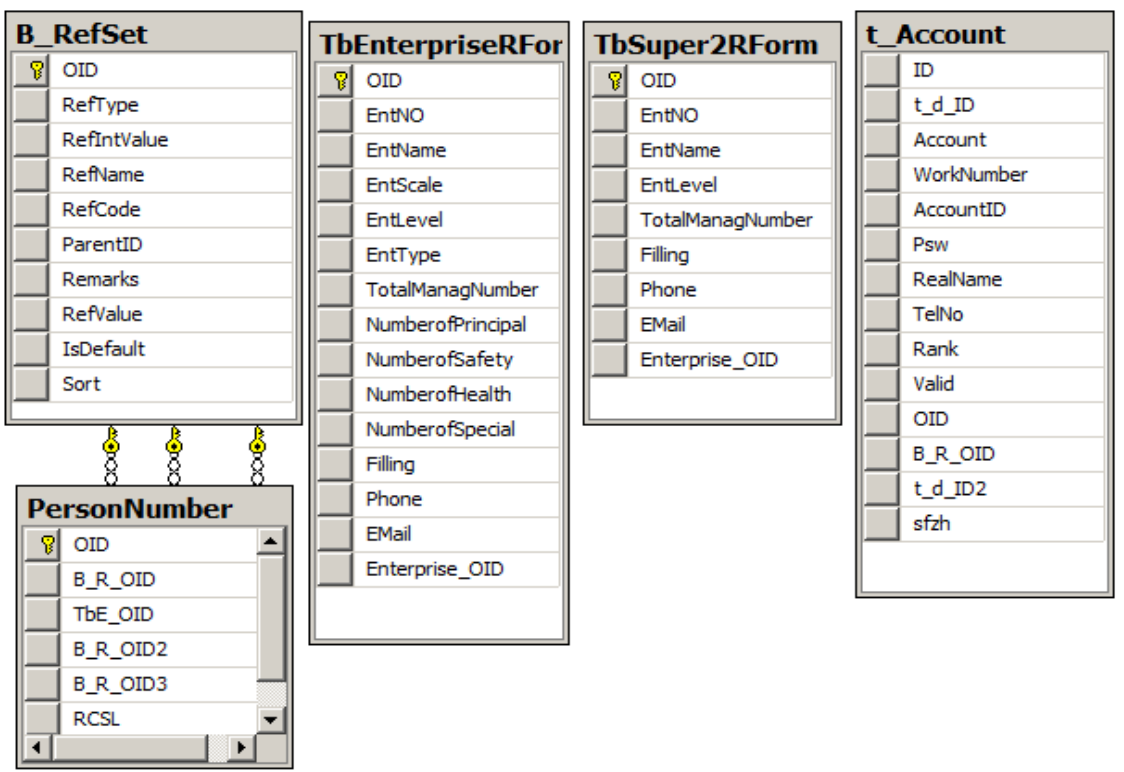

Figure 2. Relations between tables.

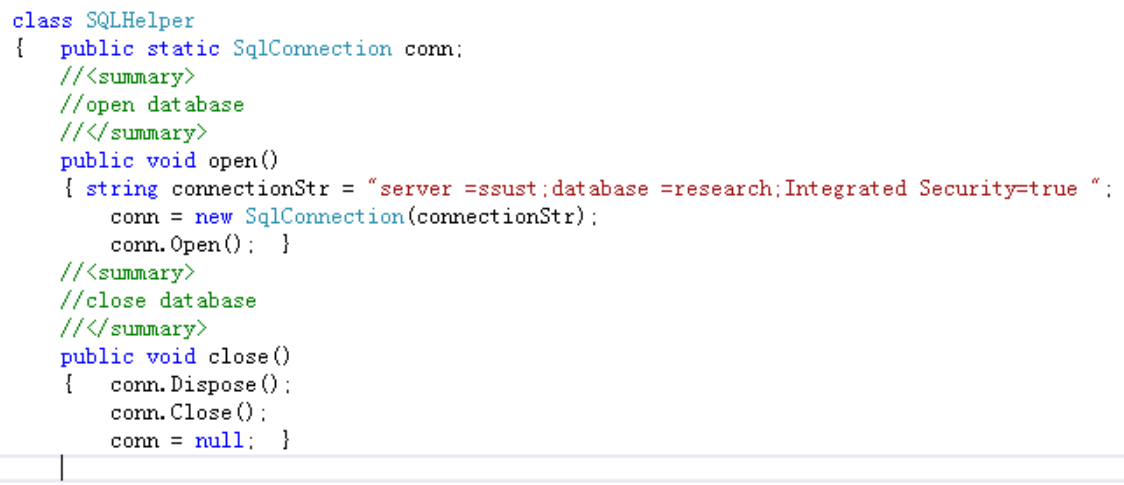

Figure 3. Connecting and closing the database.

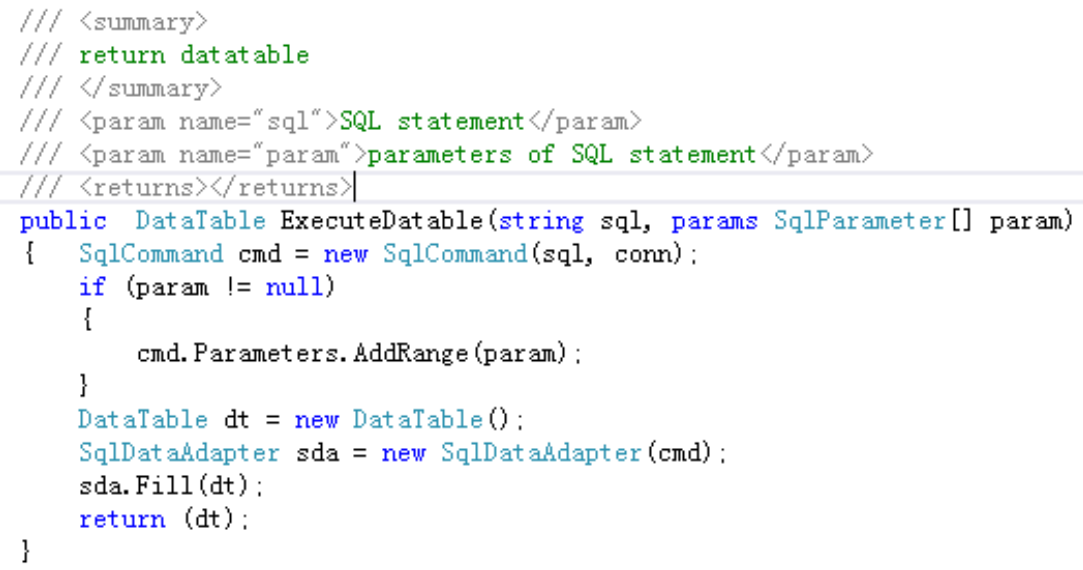

Figure 4. Query execution and return of the Datatable object.

process and results in the DBMS as well as applying the newly learned knowledge to achieving the corresponding functions. 


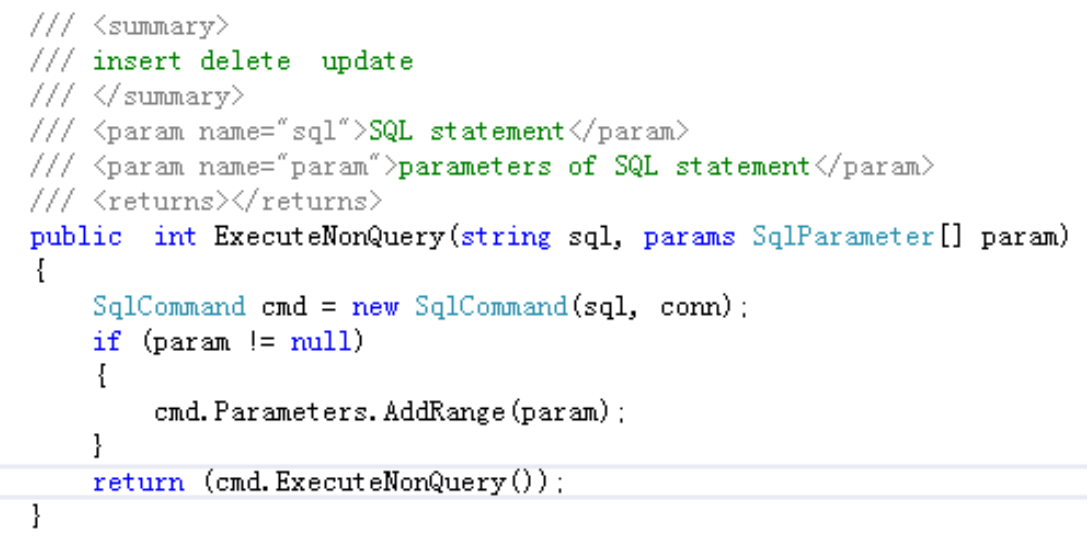

Figure 5. Basic operation using C\#.

The fourth part is all about database maintenance. We mainly teach data backup and recovery, data conversion and database security management.

The above demonstrates the face-to-face teaching content. And after that is completed, according to the feedback of the students, for the key knowledge points and difficult parts, certain reference videos are created and presented on the teaching platform. Based on the actual situation of their vocation, students are required to accomplish a demonstration project, putting forward the task requirements and completing a small database application system. The final score of this course will stem from the test score on the teaching platform, works in class, and the discussion seminar.

5) In order to expand the students' horizons and make them catch up with the fast development of the Internet, we spare no efforts to establish a solid experimental environment for our students. Our laboratory provides relational databases-MySql, SqlServer and SQLLite as well as distributed systems such as NoSQL-Memcache, MongoDB and so on. For students interested in such development software, we would offer the entry learning materials.

\section{Conclusion}

Through the implementation of the above measures, we have greatly promoted the teaching effect of the "Database Principles and Applications" of the Adult Education Correspondence Class. After intense study, the students have made significant progress in the overall understanding and application of database technology with the mastery of basic knowledge and skills. Due to the very limited study time and the fact that there are few applications in daily work and study, students have no spare time to get access to advanced skills. The development of database technology is progressing in an incredibly fast pace, and our concern finally sets foot on how to master the basic theory and skills during limited time and keep up with the technology progress.

\section{Conflicts of Interest}

The authors declare no conflicts of interest regarding the publication of this paper. 


\section{References}

[1] Wisell, K., Sporrong, S.K. and Winblad, U. (2015) The Innovation That Never Came True-Stake Holders Views of the Perceived Effects of the Reregulation of the Swedish Pharmacies. International Journal of Clinical Pharmacy, 37, 15.

[2] Hegyesi, F., Kopjak, J. and Osz, R. (2014) Educational Strategies in Adult Education. 2014 IEEE 9th International Symposium on Applied Computational Intelligence and Informatics (SACD), Timisoara, 15-17 May 2014, 177-181.

[3] Zuo, H.-W., Liang, Y. and Pan, M. (2012) Innovation of Management Model of Adult Education in the Information Age. 2012 International Symposium on Information Technology in Medicine and Education (ITME), Japan, 3-5 August 2012, 177-181.

[4] Perkovic, P. (1991) SQL Access and ANSI/ISO SQL and X/Open. COMPCON Spring'91 Digest of Papers, San Francisco, 25 Feburary-1 March 1991, 120-122.

[5] Chaudhuri, S., Chen, Z., Shim, K. and Wu, Y. (2004) Storing XML (with XSD) in SQL Databases: Interplay of Logical and Physical Designs. Proceedings of 20th International Conference on Data Engineering, Boston, MA, 2 April 2004, 842-846. 